\title{
Sales and Invoice Management System with Analysis of Customer Behaviour
}

\author{
Sanam Kadge \\ Assistant Professor, \\ Department of Information \\ Technology, \\ MHSSCOE \\ Mumbai
}

\author{
Uzair Khan \\ Student B.E, \\ Department of Information \\ Technology, \\ MHSSCOE \\ Mumbai
}

\author{
Arsalan Thange \\ Student B.E, \\ Department of Information \\ Technology, \\ MHSSCOE \\ Mumbai
}

\author{
Shamail Mulla \\ Student B.E, \\ Department of Information Technology, \\ MHSSCOE \\ Mumbai
}

\author{
Harshika Gupta \\ Student B.E, \\ Department of Information \\ Technology, \\ MHSSCOE \\ Mumbai
}

\begin{abstract}
Today, the organizations advertise and sell their products online and offline but they face the issue of managing their sales and inventory. A crucial part of their businesses is maintaining relationships with their customers, preventing them from churning out, track decreasing brand loyalty and taking steps to prevent it, and increasing profitability. This paper focuses on efficiently automating the sales processes and making a more accurate system for improving customer retention and extension, than previous software's. An extensive research done on existing systems gave us an insight into their shortcomings which this system attempts to overcome by using predictive analytics. Using decision trees and random forests in machine learning, the accuracy of the algorithm improves over time to give us better results progressively. The implementation of this system has resulted in better resource utilization, increased responsiveness and accurate forecasting of customer behaviour. This system has been implemented to seamlessly integrate with any ERP system for efficient stock management and an Android application to track the employees and keep them updated with their tasks.
\end{abstract}

\section{Keywords}

Salesforce automation, classification, predictive analytics

\section{INTRODUCTION}

Sales and Invoice management system with analysis of customer behaviour is a system that allows the organisations to manage a company's sales and invoices using technology to organize, automate and synchronize sales and invoicing activities. This is a customer-oriented feature which includes tracking of customers' lifecycle right from the point they show interest in a particular product to the time they make the purchase. The system also performs customer behaviour analysis based on the same.

The implementation of this system greatly effects customer satisfaction. Firstly, firms are able to customize their offerings for each customer by accumulating information across customer interactions and processing this information to discover hidden patterns.
Secondly, the application enables firms to provide timely, accurate processing of customer orders, requests and the ongoing management of customer accounts, vendors accounts, tracking of customers activity, converting a user into customer, contracts with vendors, products and sales information, etc.

Thirdly, it also helps firms manage customer relationships more effectively across the stages of relationship throughout the sales life cycle. And finally, the most important thing for any organisation is customer loyalty. In order to reduce customer churn, the algorithm will study the customer interactions with the organisation and predict whether the potential customer would buy a product or not.

The main objective of this system is customer satisfaction, gaining new customers and boosting sales. The analysis points out brand loyalty of customers. The software shows which brand is most popular, at which stage do the customers choose to not buy the product and why.

Thus the analytics module provides details on where there is room for improvement which will in turn boost sales.

\section{IMPLEMENTATION}

\subsection{Need for the system}

This system is a tool that helps sales people get organized, manage their contacts better and track their sales deals more efficiently. In short - a tool that helps sell more. This Sales and Invoice Management System also give sales managers a simple yet clear overview of how their team is performing - a tool that helps their teams sell better.

An integral part of any Sales and Invoice Management System is companywide integration among different departments. If Sales and Invoice Management Systems aren't adopted and properly integrated to all departments, there might be a lack of communication which could result in different departments contacting the same customer for the same purpose. In order to mitigate this redundancy and inconvenience to customers, this system must be fully integrated in all departments that deal with customer service management. 


\subsection{Existing System}

Figure 2.1 shows the different existing systems and the different sub modules in them. There are various systems available for sales management. One of them is SalesForce.com. This system is used only to manage the sales of an organization which is highly customizable. It can be used for placing an order of a product, tracking customer activities, time management activity, opportunity and account management activity. The main purpose of this system is lead tracking.

\begin{tabular}{|c|c|c|c|c|c|c|c|c|c|c|}
\hline MAIN MODULE & SUB MODULE & $\begin{array}{l}\text { MS DYNAMICS } \\
\text { (PROFESSIONAL) }\end{array}$ & $\begin{array}{c}\text { VTIGER } \\
\text { (COMMUNITY) }\end{array}$ & $\begin{array}{c}\text { Vtiger } \\
\text { (Professional) }\end{array}$ & $\begin{array}{l}\text { SUGAR CRM } \\
\text { (COMMUNITY) }\end{array}$ & $\begin{array}{l}\text { SUGAR CRM } \\
\text { (PREMIUM) }\end{array}$ & SUITECRM & 1CView & Salesforce & Zoho \\
\hline \multirow{8}{*}{ SALES } & OPPORTUNITIES & $\checkmark$ & $\checkmark$ & $\checkmark$ & $\checkmark$ & $\checkmark$ & $\checkmark$ & $\checkmark$ & $\checkmark$ & $\checkmark$ \\
\hline & LEADS & $\checkmark$ & $\checkmark$ & $\checkmark$ & $\checkmark$ & $\checkmark$ & $\checkmark$ & $\checkmark$ & $\checkmark$ & $\checkmark$ \\
\hline & COMPETITORS & $\checkmark$ & $x$ & $x$ & $x$ & $x$ & $x$ & $\checkmark$ & $\checkmark$ & $\checkmark$ \\
\hline & ACCOUNTS & $\checkmark$ & $x$ & $\checkmark$ & $\checkmark$ & $\checkmark$ & $\checkmark$ & $\checkmark$ & $\checkmark$ & $\checkmark$ \\
\hline & PROJECTS & $x$ & $\checkmark$ & $\checkmark$ & $\checkmark$ & $\checkmark$ & $\checkmark$ & $\checkmark$ & $\checkmark$ & $\checkmark$ \\
\hline & ACTIVITIES & $\checkmark$ & $x$ & $\checkmark$ & $\checkmark$ & $\checkmark$ & $\checkmark$ & $\checkmark$ & $\checkmark$ & $\checkmark$ \\
\hline & ACTIVITY TRACKING & $\checkmark$ & $x$ & $\checkmark$ & $\checkmark$ & $\checkmark$ & $\checkmark$ & $\checkmark$ & $\checkmark$ & $\checkmark$ \\
\hline & CONTRACTS & $x$ & $\checkmark$ & $\checkmark$ & $\checkmark$ & $\checkmark$ & $\checkmark$ & $\checkmark$ & $\checkmark$ & $x$ \\
\hline \multirow{9}{*}{$\begin{array}{l}\text { INVOICING AND } \\
\text { INVENTORY } \\
\text { MANAGMENT }\end{array}$} & QUOTES & $\checkmark$ & $\checkmark$ & $\checkmark$ & $x$ & $\checkmark$ & $\checkmark$ & $\checkmark$ & $\checkmark$ & $\checkmark$ \\
\hline & PURCHASE ORDERS & $\checkmark$ & $\checkmark$ & $\checkmark$ & $x$ & $x$ & $x$ & $x$ & $\checkmark$ & $\checkmark$ \\
\hline & VENDORS & $x$ & $\checkmark$ & $\checkmark$ & $x$ & $x$ & $x$ & $\checkmark$ & $\checkmark$ & $\checkmark$ \\
\hline & INVOICE & $\checkmark$ & $\checkmark$ & $\checkmark$ & $x$ & $x$ & $\checkmark$ & $\checkmark$ & $\checkmark$ & $\checkmark$ \\
\hline & PRICE BOOKS & $\checkmark$ & $\checkmark$ & $\checkmark$ & $x$ & $x$ & $x$ & $\checkmark$ & $\checkmark$ & $\checkmark$ \\
\hline & ASSETS & $x$ & $\checkmark$ & $\checkmark$ & $x$ & $x$ & $x$ & $\checkmark$ & $\checkmark$ & $x$ \\
\hline & SALES ORDER & $\checkmark$ & $x$ & $\checkmark$ & $x$ & $x$ & $x$ & $x$ & $\checkmark$ & $\checkmark$ \\
\hline & PRODUCTS & $\checkmark$ & $\checkmark$ & $\checkmark$ & $x$ & $x$ & $\checkmark$ & $\checkmark$ & $\checkmark$ & $\checkmark$ \\
\hline & SALES LITERATURE & $\checkmark$ & $x$ & $\checkmark$ & $x$ & $x$ & $x$ & $x$ & $x$ & $x$ \\
\hline \multirow{4}{*}{ SERVICES } & VISITS & $\checkmark$ & $x$ & $x$ & $x$ & $x$ & $x$ & $x$ & $\checkmark$ & $\checkmark$ \\
\hline & CASES & $\checkmark$ & $x$ & $x$ & $\checkmark$ & $\checkmark$ & $\checkmark$ & $x$ & $\checkmark$ & $\checkmark$ \\
\hline & SOLUTIONS & $\checkmark$ & $x$ & $x$ & $\checkmark$ & $\checkmark$ & $\checkmark$ & $x$ & $\checkmark$ & $\checkmark$ \\
\hline & FORECAST & $x$ & $x$ & $x$ & $x$ & $x$ & $x$ & $x$ & $\checkmark$ & $\checkmark$ \\
\hline
\end{tabular}

Figure 2.1 Comparison of existing systems

\subsection{Problems in the existing system}

The very first drawback of SalesForce.com is that it does not have the inventory and Invoice module. Inventory management module is used for tracking inventory levels, orders, sales and deliveries. It can also be used in in any manufacturing industry to create a work order, bill of materials and other production-related documents. Users cannot track the cost of the materials they use to provide services. There is no proper order management, that is, system does not tell the managers to reorder the product when it runs out of stock.

The existing system does not include an analytics module. So the sales of the organization cannot be analysed which helps the organization to understand the current sales of organization and what steps should be taken to increase the sales of the products.

Users face difficulties in transitions between transactions. The users have to go through multiple screens to process the transaction.
A comparative study of all the famous existing systems was done to find out the shortfalls and gaps among all software's, which this software intends to compensate in the system. This study is shown in the figure alongside.

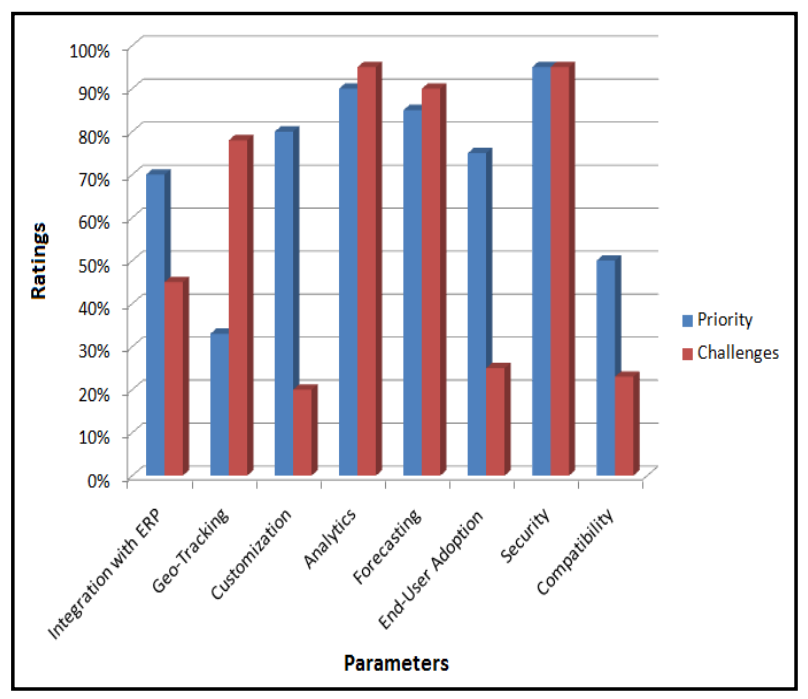

Figure 2.2 Challenges in Existing Systems

\section{PROPOSED SYSTEM}

$1 \mathrm{CView}$, a web application that helps in managing the company's sales and invoices has been developed. This web application provides a complete solution for managing 
interaction with customers, handling their data, sales, accounts, contracts, etc. This application is used for managing the company's interaction with the customer, clients and sales prospects, product purchase information, etc. This system is a customer-oriented feature which involves tracking of customer's lifecycle right from the point they show interest in a particular product to the time they make the purchase. The system will also perform customer behaviour analysis based on the same.

This web applications enables firms to provide timely, accurate processing of customer orders, requests and the ongoing management of customer accounts, vendors accounts, tracking of customers activity, converting a user into customer, contracts with vendors, products and sales information, etc. It also contains typical sales generation activities that involves building and managing a customer database (refers to all customer related information, such as contacts, requirements, buyers, etc.) and can be further used to develop one on one relationships with clients through better and effective communication. It enables organizations to clearly set rules and responsibilities in terms of who is to handle what kind of work and when. This results in improved productivity and better response to customer requirements.

\subsection{Sales Management}

The sales life cycle starts from the first phase which is leads. Leads refer to those entities who may be interested to do business with the organisation. The people who respond to various marketing strategies are referred to as opportunities. When the customer is interested in buying, the organization will quote price from the product price book. After negotiation and comparing, if the customer is ready to buy, an invoice is generated by the vendor.

Sales also include the details of the competitors. This keeps the organization updated about the various strategies applied by competitors, sale lost to them and its reasons.

\subsection{Invoice Management}

An integral part of managing the company's sales is Invoice management. This module deals with managing the products availability. The system keeps a count of each product available. Every time any product is not available, a notification is sent to the concerned employee to take appropriate action. A detailed price book is maintained for each product. Vendor details are also be maintained, to show which products belong to which vendor.

\subsection{Analytics}

The use of data mining algorithms is used to achieve the following classifications: categories types of customers and their count in each category, determining brand loyalty and overall customer behaviour of each customer during the sales life cycle will be visualized in various forms.

The most important use of analytics is to reduce customer churn. Using machine learning, the system develops knowledge about customer behaviour which will be used to predict whether a customer would churn out in the current sales life cycle. Decision trees were used to generate whether a customer would buy the product or not.

The available data is divided into test and training sets. Using 3-fold cross validation and random forests, the system improves the accuracy of the algorithm by making sure the datasets in the test set is being used for training at some point and vice versa. By choosing an optimal number of features for the given amount of data, the graph is not over or under fitted. Thus the prediction model is not too complex or oversimplified.

The output generated on each customer for a particular campaign would forewarn the sales management team to handle that customer in a specialised way, if it is important enough.

\section{IMPLEMENTATION}

The developed web application is used for maintaining sales details, handling customer and vendor data, accounts, contracts, customer and employee activity tracking. This application is used for managing the company's interaction with the customer, clients and sales prospects, product purchase information, etc. till the purchase of a product and controls every stage of the sales lifecycle.

Technologies that have been used include PHP, HTML, CSS, Python and MYSQL database for implementation. The system enables sales analysis, as well as offering high-performance statistical tools which are able to determine customer behaviour, to recognize all effective operations and brand loyalty, and to calculate new customer acquisition costs.

It has the capacity to reduce sales team workload by sharing data entry load across people. It helps to track as to which opportunities are being lost and the reasons.

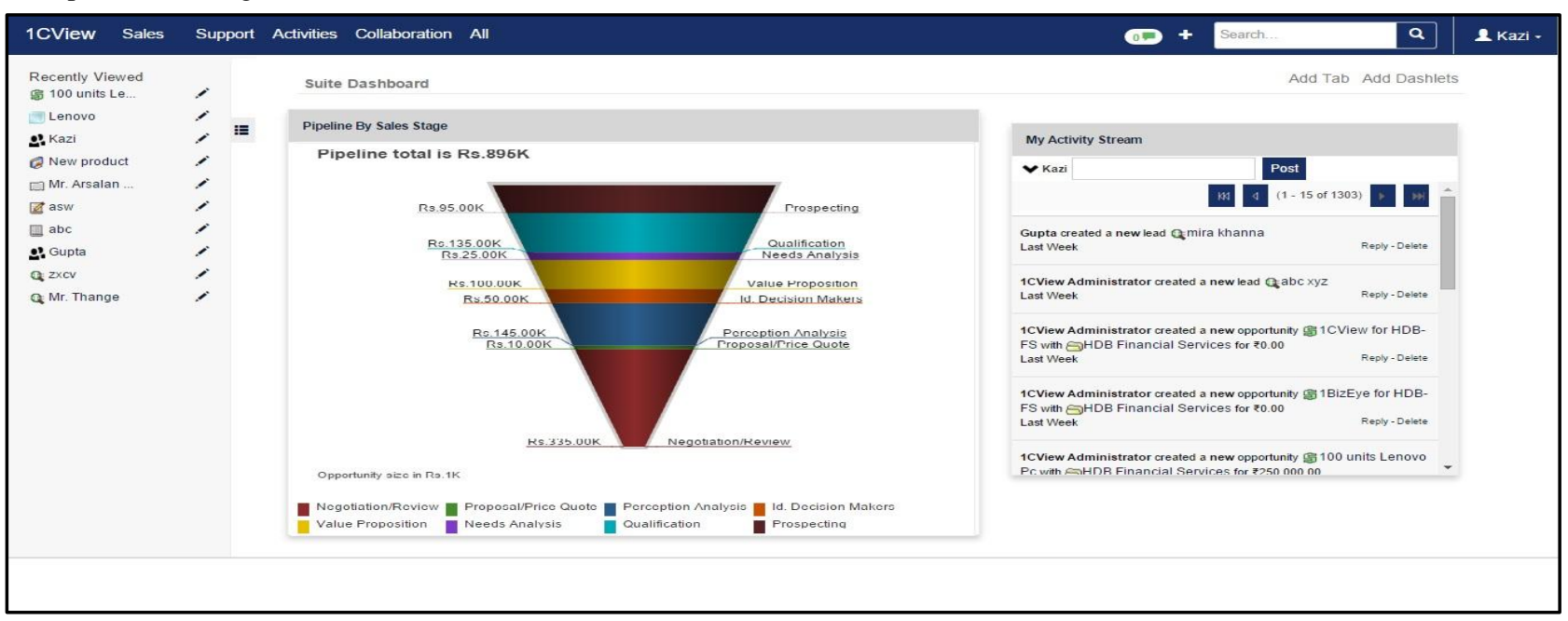

Figure 4.1 Home Screen 
Figure 4.1 shows the home screen or the dashboard of the system with different main modules in the menu bar. It keeps information about vendors that may include companies, people, and contractors from which the company gets products and services

This system contains different sub modules such as

- $\quad$ Leads

- Opportunities

- Accounts

- $\quad$ Activity tracking

- Quotes

- Invoice
- Vendor

- $\quad$ Sales order

- Products

- $\quad$ Geo-Tracking

Leads refer to those individuals or people that the organisation might have the potential to do business with. Opportunities represent those individuals that are interested in purchasing products of the organisation.

Products can be treated as goods or services, which can be sold or procured. When the purchase is made the user is converted into a customer referred to as contact.

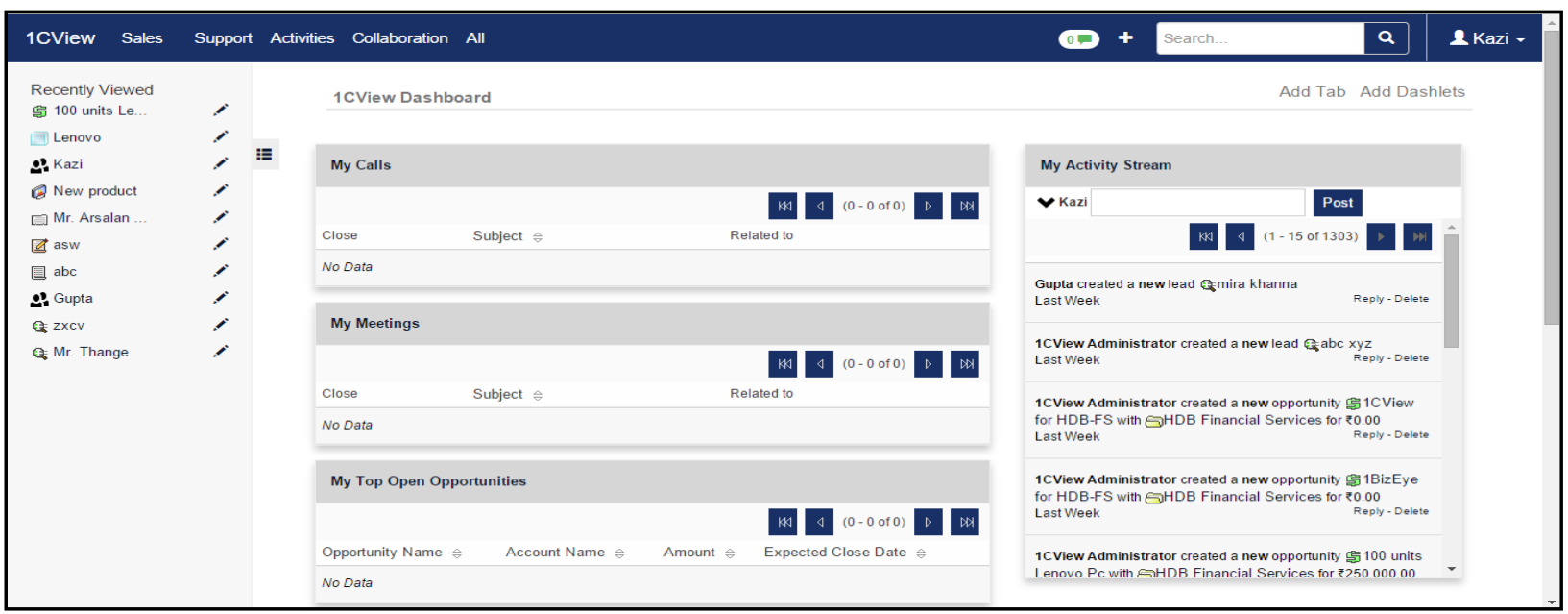

Figure 4.2 Sales Dashboard

Figure 4.2 shows the Sales view of the system with different sub modules in sales such as Quotes, accounts, leads, opportunities, etc. are associated to, contact details etc. It makes it easier to determine which products are producing more revenue and which customers drop out of the sales life cycle.

The web application contains customer's account details such as their name, address, name of the organization they

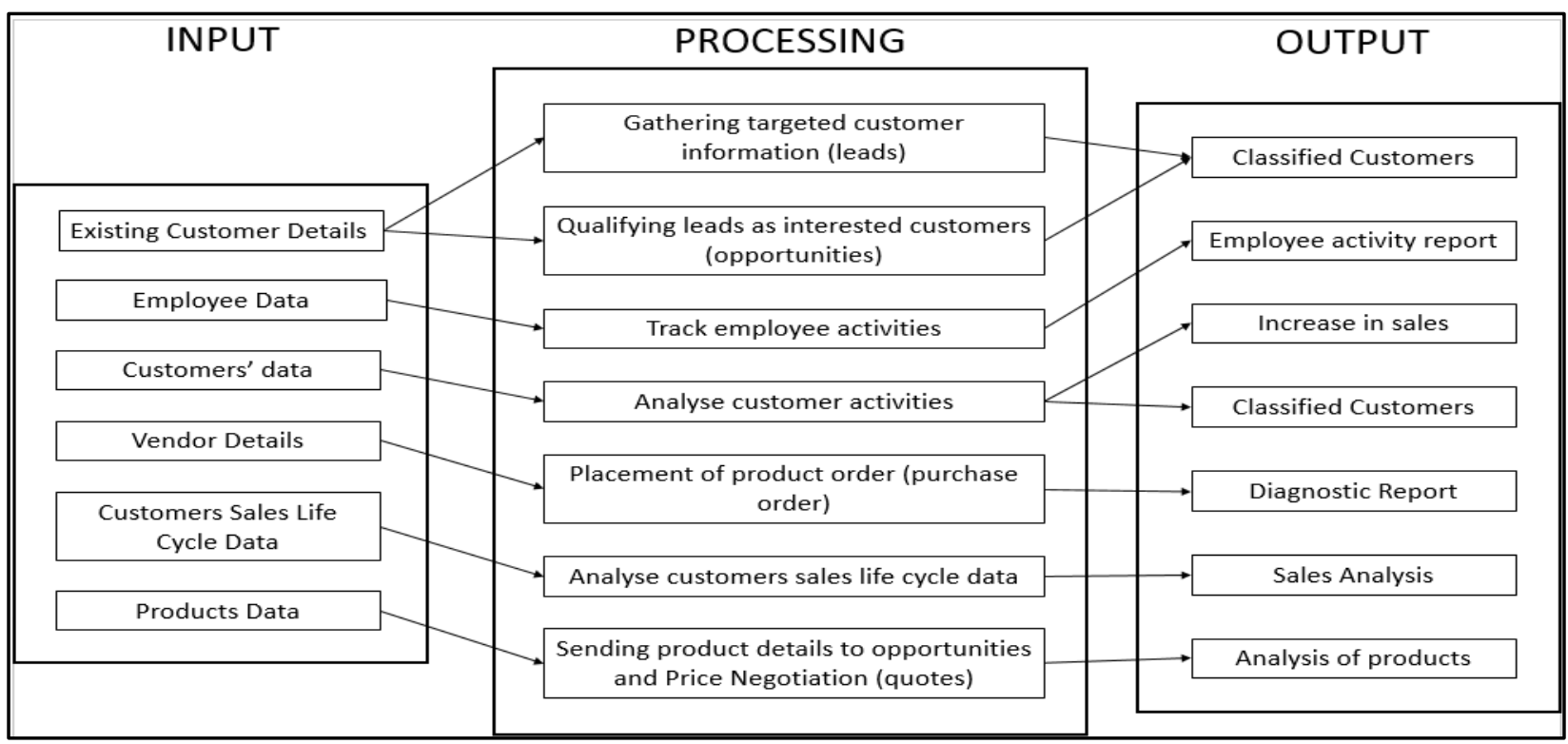

Figure 4.3: Block Diagram 
Figure 4.3 represents the working of Sales and Invoice Management System with Analysis of Customer behaviour. The system takes customer details, competitor data, vendor details and sales data as an input.

All the targeted customers who may buy the product are gathered and put in the leads table. When leads show interest in buying the product they are qualified as opportunities and price negotiation takes place. When a final quote has been decided an order is placed and the vendor performs their invoicing procedure.

The system also keeps an account of customer behaviour throughout their sales life cycle and classifies them according to their behaviour. Sale of products is also tracked and analyzed. Employee activities are tracked and customized reports can be created.

Other than the traditional reports being generated, extensive classification is performed on the data collected and displayed according to the level of granularity required by each user.

The use of data mining algorithms used to achieve the following classifications:

Categories types of customers and their count in each category, determining brand loyalty and overall customer behaviour of each customer during the sales life cycle will be visualized in various forms.

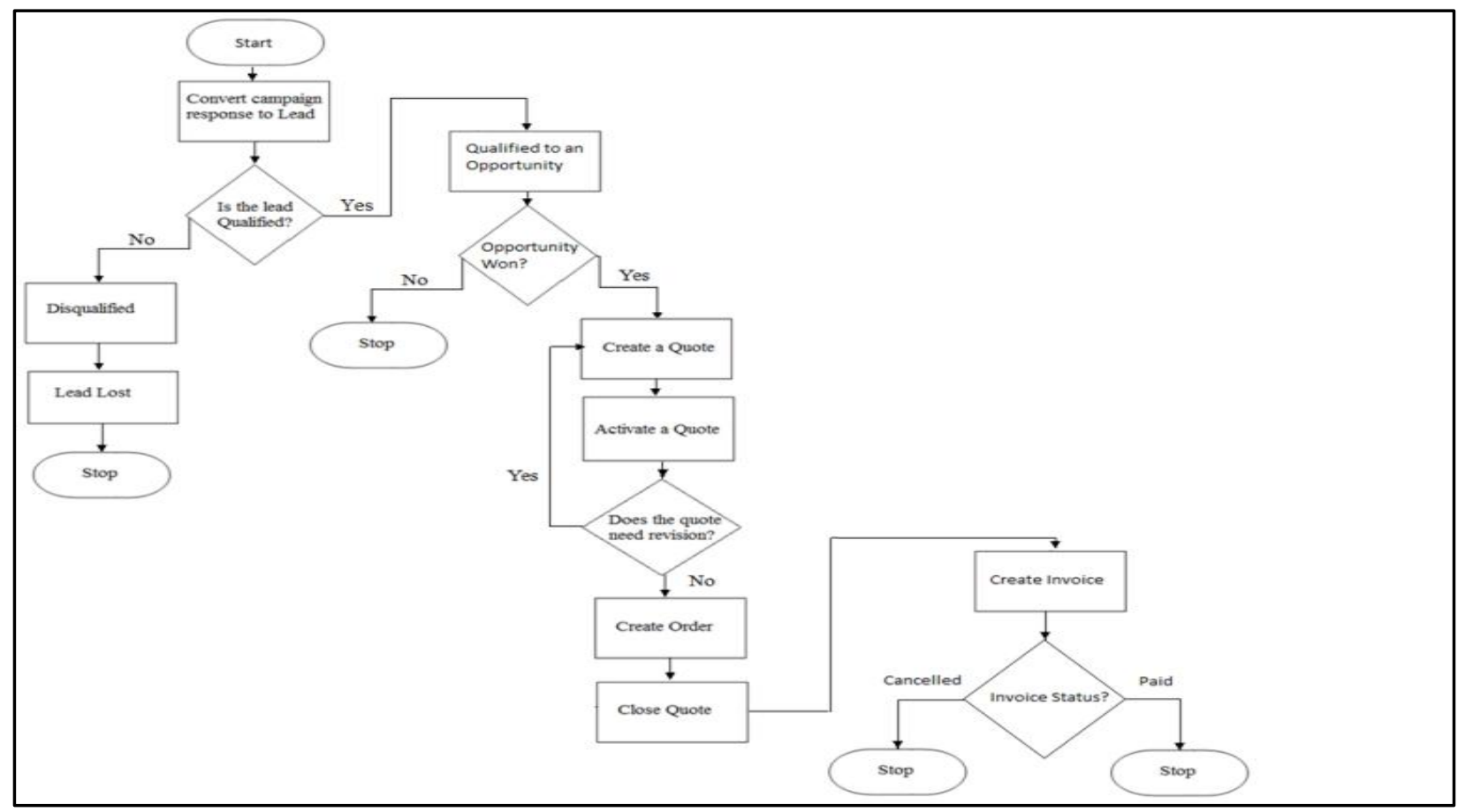

Figure 4.4 Flow chart

Figure 4.4 shows the flowchart of the system. When a potential customer responds to a marketing scheme, the contact is labelled as a 'lead'. If the organisation succeeds to get the interest of the customer in the product when they make enquiries, they are qualified as 'opportunities'. At this stage the customer asks for quotations, which are provided from the product price books. If the customer is satisfied an order will be created.

\section{RESULT ANALYSIS}

The benefit of using this system is that it provides the organisation with the following important benefits:

1. This system overcomes the customer churn by using predictive analysis. Initially, with more data and lesser understanding of the system, the model was not so effective, which is clearly evident in Figure
5.1. After further revision of code, the system proved to be more effective than before.

2. This system overcome the challenges faced in the sales management system and meets the needs of Organizations that are not satisfied by existing applications in the field of Invoice management.

3. System analysis shows the various sectors from which the organisation generates revenue. Figure 5.2 demonstrates the breakdown. 


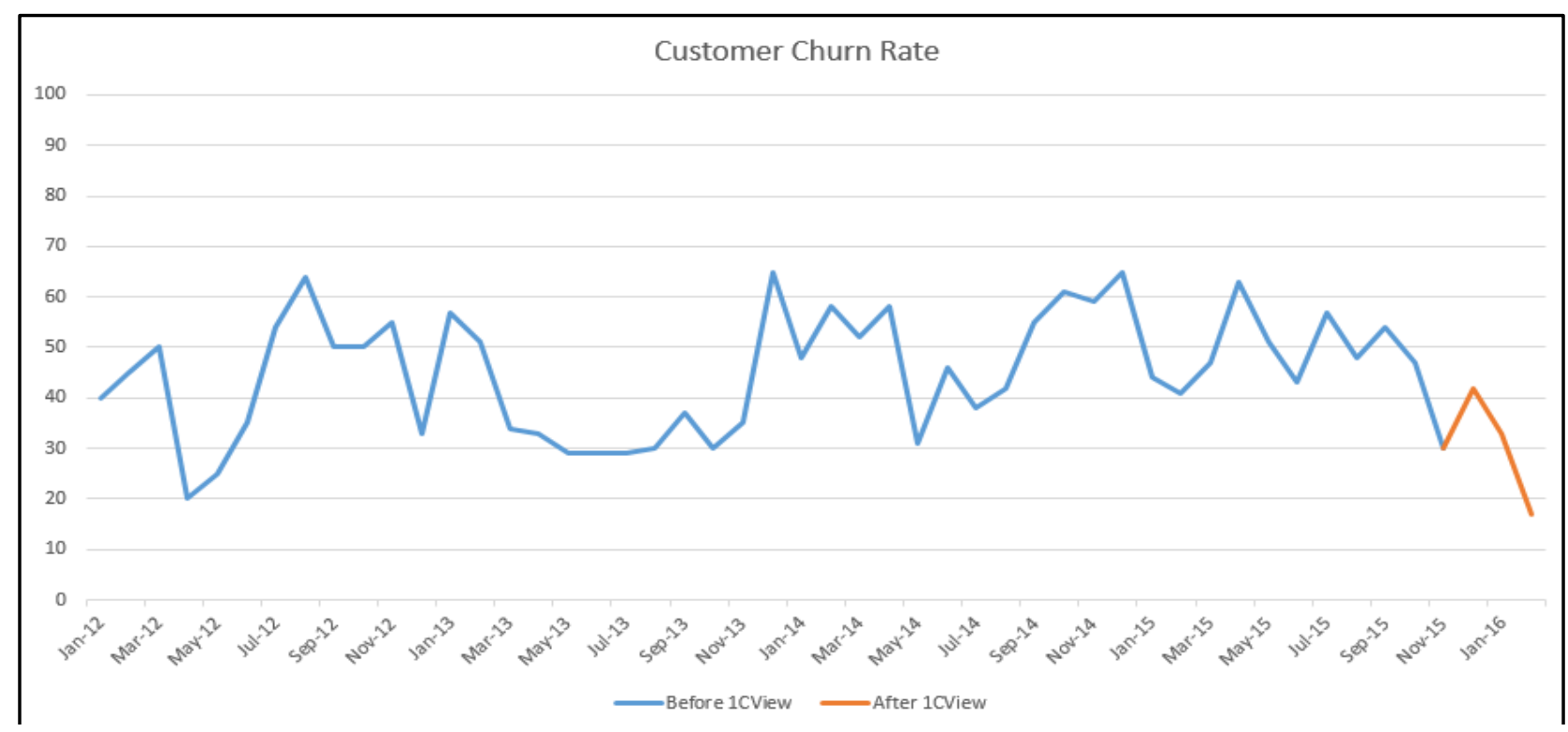

Figure 5.1: Analysis of churn while deploying 1CView

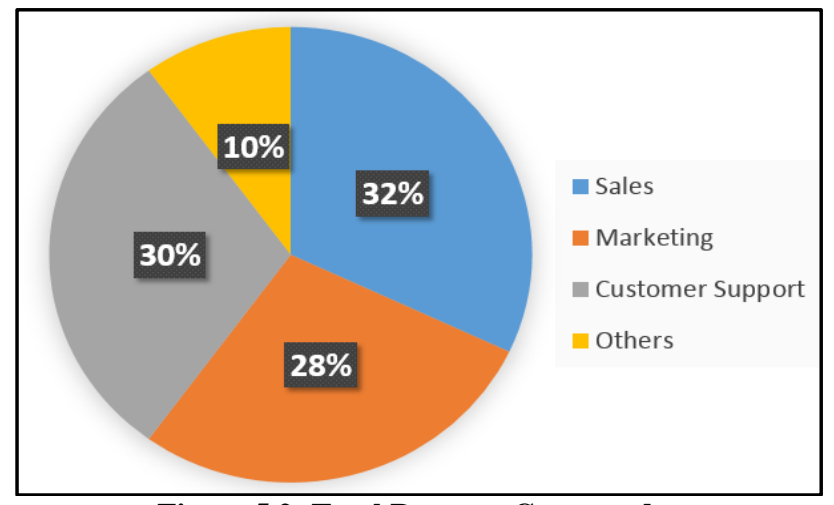

Figure 5.2: Total Revenue Generated

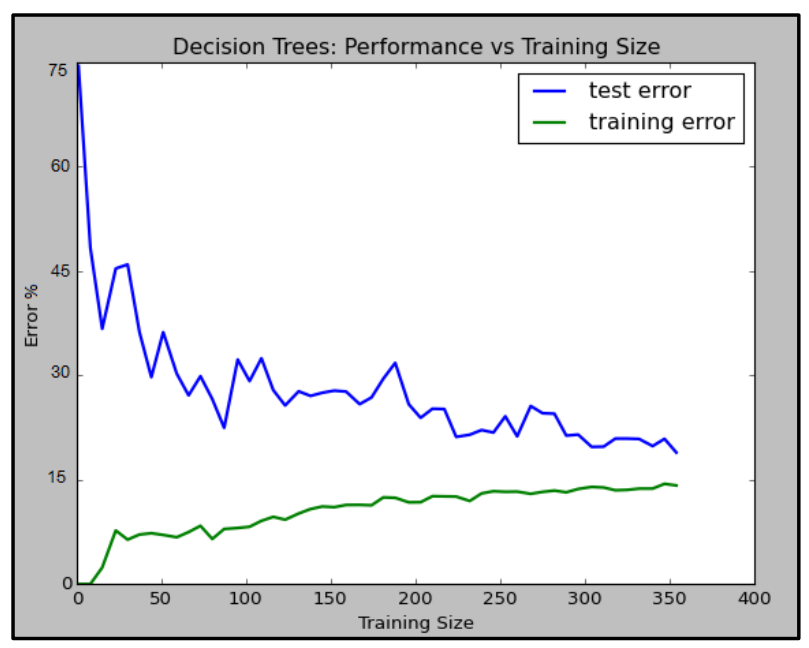

Figure 5.3: Algorithm performance with depth 5

4. Analytics being performed on data also provide the organization with meaningful information about their products and knowledge on customer behaviour. The products are be industry specific thus catering to the needs of the buyer.

5. While developing the model for predictive analytics, an optimum number of features had to be selected. The decision tree had to balance bias as a by-product of a very complex model with variance in results, by managing its depth. Comparing figure 5.3 and 5.4, we can see that by increasing the depth of the tree from 5 to 10 , error in the training and testing sets reduces greatly. Thus by increasing the depth of the tree more, we get the results visible in figure 5.5.

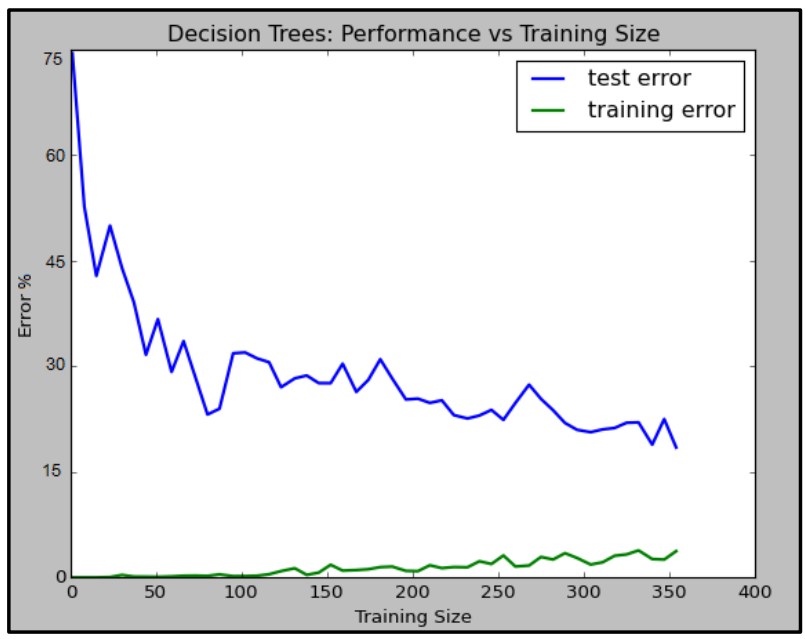

Figure 5.4: Algorithm performance with depth 10 


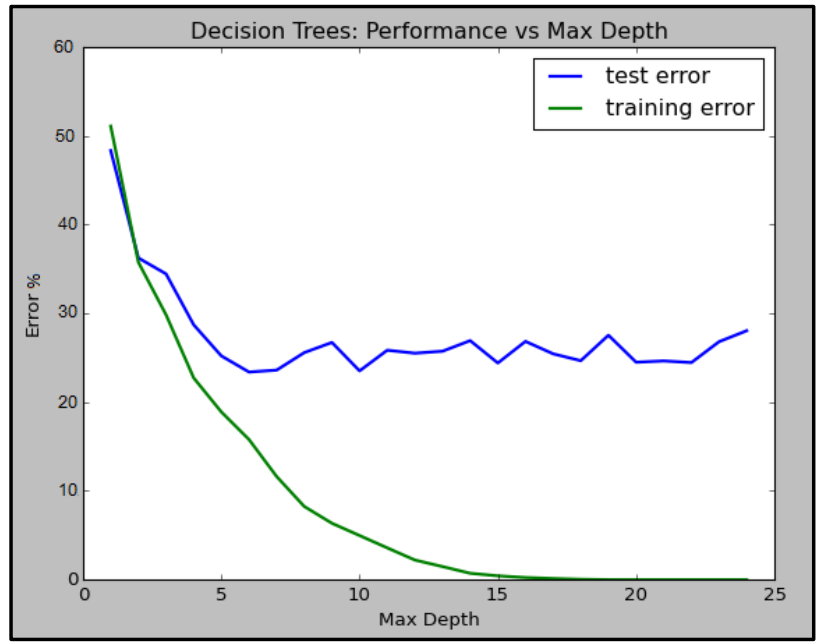

Figure 5.5: Algorithm performance with increasing depth

\section{CONCLUSION}

Sales and Invoice Management is an important aspect of any organization that must be handled skillfully. The implementation of these processes has made the working more efficient, keeps the employees up-to-date and administrators are well informed to take important decisions. Existing systems have various missing aspects that is covered by the system, making it a better alternative.

Another highlight of this system is that it extracts knowledge from data which goes beyond traditional charting tools to determine critical information about customer loyalty, product popularity, employee efficiency and overall organizational success. The meaningful information collected over time using data mining is the most exciting and useful functionality for the decision makers which helps them to discover and track new trends. Decision trees were used for predicting customer churn it was very successful. Although the error rate observed in experiments performed on testing data is relatively higher than the training data, making it seem like the data has been overfit, with more data generated over time these errors will reduce. When the usage of application increases under the supervised learning environment, the algorithm will learn from more patterns and predict much better for new data points.
'Sales and Invoice Management System with Analysis of Customer Behavior' is a very promising system and aims to enhance the user and customer experience.

\section{REFERENCES}

[1] Hee-Woong Kim, Shan L. Pan, January 2006, “Towards a process model of information systems implementation: the case of customer relationship management (CRM)"

[2] P. Senthil Vadivu, Vasantha Kalyani David, 2012, "Optimized feature extraction and actionable knowledge discovery for Customer Relationship Management (CRM)"

[3] Addison-Wesley Longman Publishing Co., Inc, "The CRM Handbook".

[4] Ralph Kimball, "The Data Warehouse Toolkit"

[5] Khawaja A. Saeed, Varun Grover, SuboGuha, William J. Kettinger, May 2011, Volume 42 Issue 2"The successful implementation of customer relationship management (CRM) system projects"

[6] Brendan Andrew Duncan, Charles Peter Elcan, 2015, "Probabilistic Modeling of a Sales Funnel to Prioritize Leads"

[7] Gurpreet Singh Matharu, Anju Mishra, Harmeet Singh, Priyanka Upadhyay, February 2015, "Empirical Study of Agile Software Development Methodologies: A Comparative Analysis"

[8] S.Babu, Dr. N. R. Ananthanarayanan, V. Ramesh, March - 2014, Vol. 3 Issue 3 "A Survey on Factors Impacting Churn in telecommunications using Datamining Techniques"

[9] Sarada Sowjanya. C., R. M. Sravan Ch, November 2013 , Vol. 2 Issue 11 "Applications of Datamining Techniques for Customer Relationship Management"

[10] Sunita Beniwal, Jitender Arora, August - 2012,Vol.1 Issue 6 "Classification and Feature Selection Techniques in Data Mining “ 